\title{
Glutathione Transport: A New Role for PfCRT in Chloroquine Resistance
}

\author{
Eva-Maria Patzewitz,,2,* J. Enrique Salcedo-Sora,, ${ }^{3,{ }^{*}}$ Eleanor H. Wong,, Sonal Sethia, Paul A. Stocks, ${ }^{3}$ \\ Spencer C. Maughan, ${ }^{4}$ James A.H. Murray, ${ }^{4}$ Sanjeev Krishna, ${ }^{5}$ Patrick G. Bray, ${ }^{3}$ \\ Stephen A. Ward, ${ }^{3}$ and Sylke Müller ${ }^{1}$
}

\begin{abstract}
Aims: Chloroquine (CQ) kills Plasmodium falciparum by binding heme, preventing its detoxification to hemozoin in the digestive vacuole (DV) of the parasite. CQ resistance (CQR) is associated with mutations in the DV membrane protein P. falciparum chloroquine resistance transporter (PfCRT), mediating the leakage of CQ from the DV. However, additional factors are thought to contribute to the resistance phenotype. This study tested the hypothesis that there is a link between glutathione (GSH) and CQR. Results: Using isogenic parasite lines carrying wild-type or mutant pfcrt, we reveal lower levels of GSH in the mutant lines and enhanced sensitivity to the GSH synthesis inhibitor L-buthionine sulfoximine, without any alteration in cytosolic de novo GSH synthesis. Incubation with $N$-acetylcysteine resulted in increased GSH levels in all parasites, but only reduced susceptibility to CQ in PfCRT mutant-expressing lines. In support of a heme destruction mechanism involving GSH in CQR parasites, we also found lower hemozoin levels and reduced CQ binding in the CQR PfCRT-mutant lines. We further demonstrate via expression in Xenopus laevis oocytes that the mutant alleles of Pfcrt in CQR parasites selectively transport GSH. Innovation: We propose a mechanism whereby mutant pfcrt allows enhanced transport of GSH into the parasite's DV. The elevated levels of GSH in the DV reduce the level of free heme available for CQ binding, which mediates the lower susceptibility to CQ in the PfCRT mutant parasites. Conclusion: PfCRT has a dual role in CQR, facilitating both efflux of harmful CQ from the DV and influx of beneficial GSH into the DV. Antioxid. Redox Signal. 19, 683-695.
\end{abstract}

\section{Introduction}

U NTIL THE WIDESPREAD EMERGENCE of parasite resistance, the antimalarial chloroquine (CQ) was one of the most important drugs ever developed. Despite its clinical importance, the molecular basis of CQ resistance (CQR) is still not fully resolved. CQ action depends on binding to heme, a toxic byproduct of host hemoglobin degradation by the malaria parasite Plasmodium falciparum. This degradation occurs in the digestive vacuole (DV) of the intraerythrocytic parasite (8), with the heme generated not being destroyed enzymatically,

\section{Innovation}

We provide data that support a novel hypothesis for the role of mutant Plasmodium falciparum chloroquine resistance transporter (PfCRT) in the chloroquine resistance phenotype. The data indicate that mutant PfCRT facilitates the redistribution of glutathione (GSH) from the cytoplasm to the digestive vacuole. This results in GSH-dependent removal of heme-binding sites, both directly by occupying them and indirectly through causing heme breakdown, which is a significant contributor to the decrease in chloroquine susceptibility.

\footnotetext{
${ }^{1}$ Institute of Infection, Immunity and Inflammation, College of Medical, Veterinary and Life Sciences, University of Glasgow, Glasgow, United Kingdom.

${ }^{2}$ Faculty of Medical and Health Sciences, University of Nottingham, Nottingham, United Kingdom.

${ }^{3}$ Molecular and Biochemical Parasitology Group, Liverpool School of Tropical Medicine, Liverpool, United Kingdom.

${ }^{4}$ School of Biosciences, Cardiff University, Cardiff, United Kingdom.

${ }^{5}$ Cellular and Molecular Medicine, St. George's, University of London, London, United Kingdom.

*These authors have contributed equally.
} 
but instead being converted into a relatively inert biocrystal called hemozoin (34). The binding of CQ to heme inhibits hemozoin formation, thus resulting in a build-up of free heme and CQ-heme complexes, which results in inhibition of parasite growth and eventually parasite death (44).

CQR correlates with reduced accumulation of drug in the parasite due to diminished drug-heme binding in the DV, although other interpretations have been recently suggested $(5,7)$. CQR is associated with polymorphisms within the DV transmembrane protein PfCRT $(11,17,18,42)$. A K76T mutation in PfCRT is conserved in all CQR parasites and is considered key in mediating the CQR phenotype (18). However, there is a wide variation in the response to CQ of cloned parasite lines containing identical mutant $p f c r t$ alleles, which indicates the involvement of additional mechanisms contributing to CQR. The multidrug-resistant homolog gene $p$ fmdr1 is probably one $(12,32,37)$, but it is likely that other factors also modify susceptibility to CQ.

Research reported during the last three decades has pointed to glutathione (GSH), the major antioxidant thiol in the parasite (2), playing some part in CQR $(1,13,14)$. One possible mechanism would be that GSH reduces heme-binding sites for CQ in some way. We postulated that different concentrations of membrane-impermeant GSH in the DV of CQR and chloroquine-sensitive (CQS) parasites could be the basis of such a mechanism. To investigate this, GSH concentrations have been compared between the CQS and CQR lines. The data generated, however, have been difficult to interpret, as isolates with different genetic backgrounds were used (30). It is thought that such lines have variable transcriptional and translational regulation of oxidative defenses and efflux transporters such as PfMRP1, which affects GSH levels (23, 31, 36). Thus, we have now analyzed in this study isogenic parasite lines, which differ only in their substituted pfcrt allele (Table 1) (42). We have confirmed that GSH is generated in the cytoplasm and demonstrate that artificially increasing GSH levels has little effect on CQ sensitivity unless the parasites also harbor mutant alleles of $p f c r t$. Moreover, we show that mutant PfCRT can transport GSH. This newly discovered function facilitates GSH redistribution from the cytoplasm into the DV selectively in the CQR lines. The data generated have allowed us to postulate a CQ resistance mechanism in which GSH is selectively transferred into the DV via mutant

Table 1. Genotypes and Phenotypes of Parasites Used IN THIS STUdY

\begin{tabular}{|c|c|c|}
\hline Parasite line & Genetic modification & Susceptibility to CQ \\
\hline GC03 & NONE & Sensitive \\
\hline $\mathrm{Dd} 2$ & NONE & Resistant \\
\hline $\mathrm{C} 2^{\mathrm{G}} \mathrm{C} 03$ & $\begin{array}{l}\text { crt locus of GC03 replaced } \\
\text { by GC03 crt locus (42) }\end{array}$ & Sensitive \\
\hline $\mathrm{C} 3^{\mathrm{Dd} 2}$ & $\begin{array}{l}\text { crt locus of GC03 replaced } \\
\text { by Dd2 crt locus (42) }\end{array}$ & Resistant \\
\hline$C 6^{7 \mathrm{G} 8}$ & $\begin{array}{l}\text { crt locus of GC03 replaced } \\
\text { by } 7 \mathrm{G} 8 \text { crt locus (42) }\end{array}$ & Resistant \\
\hline $\mathrm{T} 76 \mathrm{~K}-1^{\mathrm{Dd} 2}$ & $\begin{array}{l}\text { crt locus of Dd2 replaced } \\
\text { by Dd2 crt locus T to } \\
\text { K back mutant ( } 9 \text { ) }\end{array}$ & Sensitive \\
\hline $\mathrm{C}-1^{\mathrm{Dd} 2}$ & $\begin{array}{l}\text { crt locus of Dd2 replaced } \\
\text { by Dd2 crt locus (18) }\end{array}$ & Resistant \\
\hline
\end{tabular}

$\mathrm{CQ}$, chloroquine.
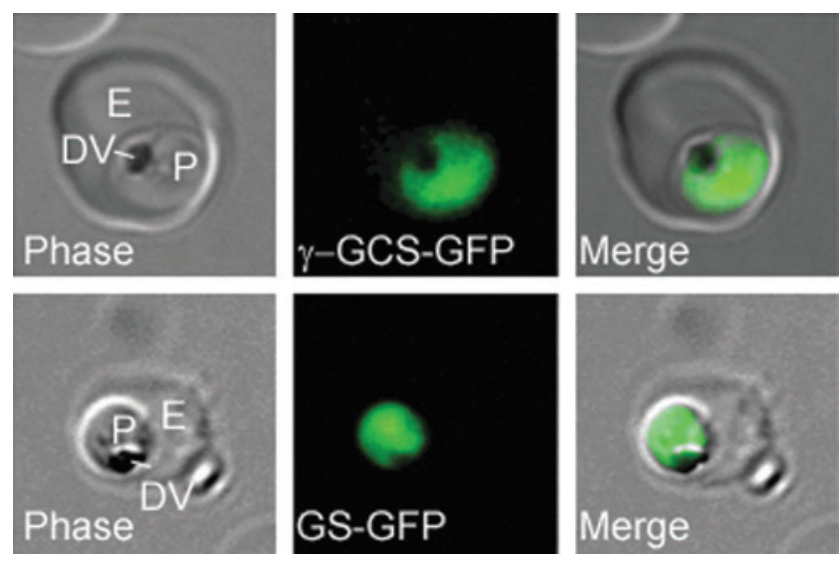

FIG. 1. Localization of Plasmodium falciparum $\gamma$-glutamylcysteine synthetase-green fluorescent protein (Pf $\gamma$ GCSGFP) and glutathione synthetase-GFP (PfGS-GFP). P. falciparum GS and $\gamma$ GCS C-terminally tagged with GFP were expressed in P. falciparum D10 erythrocytic stages. Fluorescence was analyzed using an Axioskop-2 mot plus microscope (Zeiss) equipped with a Hamamatsu C4742-95 CCD camera and was shown to be present throughout the cytoplasm of both transfected parasite lines, suggesting that GSH biosynthesis is cytoplasmic. No fluorescence is seen in the digestive vacuoles (DV) of the parasites or the erythrocyte host cell (E). $\mathrm{E}$, erythrocyte; $\mathrm{P}$, parasite; DV, digestive vacuole with hemozoin crystals.

$p f c r t$, where it competes with CQ for heme binding and results in destruction of heme, and thereby protects the parasites from the prooxidant activity of the CQ-heme complex.

\section{Results}

\section{Localization of GSH biosynthesis enzymes}

$P$. falciparum possesses genes encoding $\gamma$-glutamylcysteine

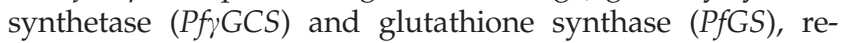
quired for GSH synthesis $(24,29)$. C-terminally tagged green fluorescent protein (GFP) variants of each gene were transfected into $P$. falciparum, and the resultant line expressed proteins were both localized to the parasite cytosol (Fig. 1).

\section{GSH levels in isogenic lines and their susceptibility to GSH-depleting agents}

Total GSH levels of isogenic parasite lines GC03, $\mathrm{C}^{\mathrm{GC}}{ }^{\mathrm{G}}$, $\mathrm{C} 3^{\mathrm{Dd} 2}$, and $\mathrm{C}^{7 \mathrm{G} 8}$ (Table 1 ) were determined using a validated HPLC method $(42,51)$. Transfected parasites carrying the Dd2 or 7G8 pfcrt CQR alleles contained significantly less GSH than the lines carrying the sensitive HB3 wild-type $p f c r t$ allele (Fig. 2A). We also determined the GSH levels of the nonisogenic untransformed CQR Dd2 standard laboratory parasite line (see Table 1) and found no significant difference in GSH content between this line and the isogenic CQS parasites whose genotype is that of GC03 (see Table 1) (Dd2, $984 \pm 184 \mathrm{nmol} / 10^{10}$ cells; C2 $\left.{ }^{\mathrm{GC} 03}, 1152 \pm 93 \mathrm{nmol} / 10^{10} \mathrm{cells}\right)$. These data highlight the importance of our use of the isogenic parasite lines, because this allowed us to probe specifically the effect of mutations in crt on GSH levels and avoided the problems associated with the confounding effects of other compensatory changes that would be likely to have occurred in untransformed CQR isolates. 

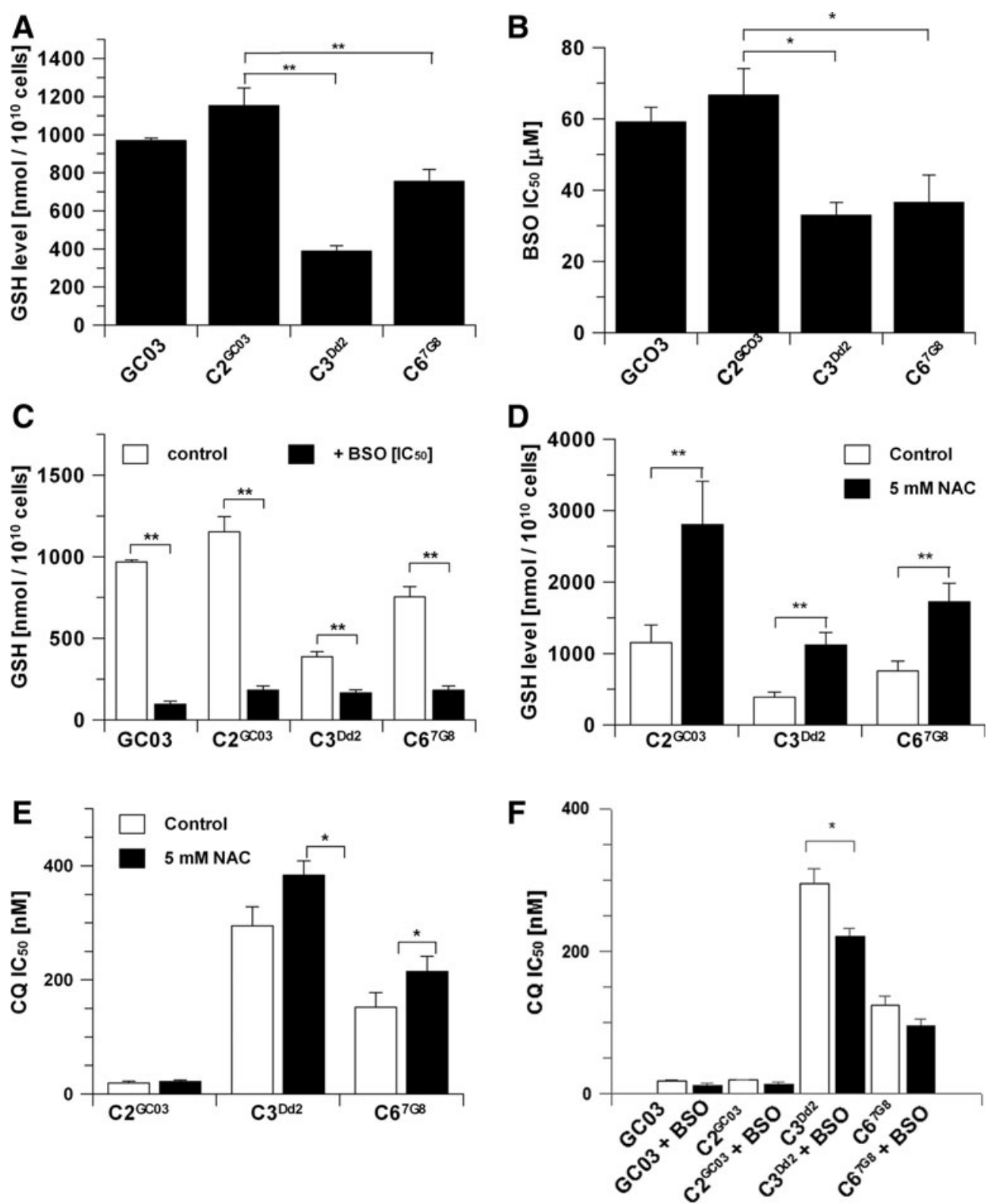

FIG. 2. Glutathione (GSH) levels, susceptibility to L-buthionine sulfoximine (BSO) and the effect of $N$-acetylcysteine (NAC) on chloroquine (CQ) susceptibility. (A) The GSH levels in C $3^{\mathrm{Dd} 2}\left(388 \pm 29 \mathrm{nmol} / 10^{10}\right.$ cells, $\left.n=6\right)$ and $\mathrm{C} 6^{7 \mathrm{G} 8}$ $\left(754 \pm 61 \mathrm{nmol} / 10^{10}\right.$ cells, $\left.n=5\right)$ were significantly lower than those determined in $\mathrm{C}^{\mathrm{GC} 03}\left(1152 \pm 93 \mathrm{nmol} / 10^{10} \mathrm{cells}, n=6\right)$ and GC03 (968 $\pm 12 \mathrm{nmol} / 10^{10}$ cells, $\left.n=3\right)(* * p<0.01$, one-way analysis of variance (ANOVA) with Newman-Keuls post-test). Data represent means \pm S.E.M. (B) $\mathrm{IC}_{50}$ values for BSO (48 h assay) for the CQR parasite lines $\mathrm{C}^{\mathrm{Dd} 2}\left(\mathrm{IC}_{50}: 32.9 \pm 3.5 \mu M\right)$ and $\mathrm{C}^{7 \mathrm{G} 8}\left(\mathrm{IC}_{50}: 36.5 \pm 7.7 \mu \mathrm{M}\right)$ were significantly lower than that of CQS C2 ${ }^{\mathrm{GC} 03}$ and GC03 $\left(\mathrm{IC}_{50}: 60.3 \pm 8.3 \mu \mathrm{M}\right.$ and $\left.59.1 \pm 4.1 \mu \mathrm{M}\right)$ $\left({ }^{*} p<0.05\right.$, one-way ANOVA with Newman-Keuls post-test). Data represent means \pm S.E.M. $(n=9)$. (C) Parasite lines were exposed to $\mathrm{IC}_{50}$ concentrations of BSO for $2 \mathrm{~h}$ before GSH levels were determined. GSH levels decreased significantly in all 4 parasite lines: from $968 \pm 12$ to $97 \pm 17 \mathrm{nmol} / 10^{10}$ cells for GC03; from $1152 \pm 93$ to $183 \pm 24 \mathrm{nmol} / 10^{10}$ cells for C2 ${ }^{\mathrm{GC} 03}$; from $388 \pm 29$ to $166 \pm 19 \mathrm{nmol} / 10^{10}$ cells for $\mathrm{C}^{\mathrm{Dd} 2}$; and from $754 \pm 61$ to $183 \pm 24 \mathrm{nmol} / 10^{10}$ cells for C6 ${ }^{7 \mathrm{G} 8}$. Data represent means \pm S.E.M. of two to six independent measurements $\left({ }^{* *} p<0.01\right.$, one-way ANOVA with Newman-Keuls post-test). (D) The levels of GSH in $\mathrm{C} 2{ }^{\mathrm{GC} 03}, \mathrm{C} 3{ }^{\mathrm{Dd} 2}$, and $\mathrm{C}^{7 \mathrm{G} 8}$ were determined after incubation without or with $5 \mathrm{mM}$ NAC for $16 \mathrm{~h}$. The levels of the GSH increased significantly in all three parasite lines analyzed to from $1152 \pm 93$ to $2800 \pm 600 \mathrm{nmol} / 10^{10}$ cells for $\mathrm{C}{ }^{\mathrm{GC} 03}$; from $388 \pm 29 \mathrm{nmol} / 10^{10}$ cells to $1120 \pm 180 \mathrm{nmol} / 10^{10}$ cells for $\mathrm{C}^{\mathrm{Dd} 2}$; and from $754 \pm 61 \mathrm{nmol} / 10^{10}$ cells to $1720 \pm 260 \mathrm{nmol} / 10^{10}$ cells for $\mathrm{C}^{7 \mathrm{G} 8}$. Data represent means \pm S.E.M. of two independent experiments each done in triplicate $\left({ }^{* *} p<0.01\right.$; one-way ANOVA with Newman-Keuls post-test). (E) The effect of $5 \mathrm{mM}$ NAC on the susceptibility to CQ was determined. In a normal medium, $\mathrm{IC}_{50}$ s were $19.2 \pm 3.2 \mathrm{n} M, 295 \pm 33 \mathrm{n} M$, and $152 \pm 25 \mathrm{nM}$ for $\mathrm{C}^{\mathrm{GC} 03}, \mathrm{C} 3^{\mathrm{Dd} 2}$, and C6 $6^{7 \mathrm{G} 8}$, respectively. In the presence of $5 \mathrm{mM} N A C$, the $\mathrm{IC}_{50}$ s increased significantly in $\mathrm{C} 3^{\mathrm{Dd} 2}$ to $384 \pm 25 \mathrm{nM}$ and in CQR C6 ${ }^{7 \mathrm{G} 8}$ to $215 \pm 27 \mathrm{nM}\left({ }^{*} p<0.05\right.$; one-way ANOVA with Newman-Keuls post-test), while the $\mathrm{IC}_{50}$ for $\mathrm{C} 2{ }^{\mathrm{GC} 03}(21.9 \pm 3.0 \mathrm{nM})$ was not significantly different. Data represent means \pm S.E.M. of three to four independent experiments each done in triplicate. $(\mathrm{F}) \mathrm{The}$ effect of preincubating parasite lines with $30 \mu \mathrm{M}$ BSO (CQR) or $60 \mu \mathrm{M}$ BSO (CQS) on their susceptibility to CQ for $20 \mathrm{~h}$ was analyzed. The $\mathrm{IC}_{50}$ values decreased from $18.3 \pm 0.9 \mathrm{n} M$ to $11.5 \pm 3.7 \mathrm{n} M$ in $\mathrm{GC} 03 ; 19.3 \pm 1.2 \mathrm{n} M$ to $13.0 \pm 4.1 \mathrm{nM}$ in $\mathrm{C}^{\mathrm{GC} 03}$; from $296 \pm 21 \mathrm{n} M$ to $222 \pm 11 \mathrm{n} M$ in $\mathrm{C}^{\mathrm{Dd} 2}$; and from $125 \pm 12 \mathrm{n} M$ to $93.3 \pm 9.3 \mathrm{n} M$ in $\mathrm{C}^{7 \mathrm{G} 8}$. The reduction of the CQ $\mathrm{IC}_{50}$ in $\mathrm{C}^{\mathrm{Dd} 2}$ was significant $\left({ }^{*} p<0.05\right.$; one-way ANOVA with Newman-Keuls post-test). 
To elucidate whether the isogenic lines were differentially affected by the specific $\gamma$ GCS inhibitor L-buthionine sulfoximine (BSO), the $\mathrm{IC}_{50}$ values of $\mathrm{BSO}$ were determined (Fig. 2B). Consistent with the lower GSH levels in the CQR lines, the $\mathrm{IC}_{50}$ values for BSO of these parasites were approximately half those of the CQS lines (Fig. 2B). It was further verified that the lethal effect of BSO was associated with GSH depletion. $\mathrm{BSO}$ treatment at $\mathrm{IC}_{50}$ concentrations (for $2 \mathrm{~h}$ ) resulted in significant decreases of GSH levels in all four parasite lines (Fig. 2C).

\section{Susceptibility of parasite lines to $C Q$ and the effect of $\mathrm{N}$-acetylcysteine}

Incubating the isogenic parasites with $5 \mathrm{mM} \mathrm{N}$ acetylcysteine (NAC) for $16 \mathrm{~h}$ increased intracellular GSH levels in the CQS C2 ${ }^{\mathrm{GC} 03}$ line by more than twofold (Fig. 2D) without causing a significant change in the response to $C Q$, the $\mathrm{IC}_{50}$ ratio being 1.1 (Fig. 2E). In contrast, increasing GSH levels in the CQR parasites $\mathrm{C} 3^{\mathrm{Dd} 2}$ and $\mathrm{C} 6^{7 \mathrm{G} 8}$ (Fig. 2D) led to statistically significant increases of the $\mathrm{CQ} \mathrm{IC}_{50}$ values of both lines (Fig. 2E). These data support the case that elevated GSH levels in the presence of the mutant crt gene mediate a further increase in the resistance to CQ. Additional supporting evidence for the involvement of GSH and CRT was provided by the demonstration that a decrease in GSH levels by preincubation of parasites with BSO resulted in a significant reduction in $\mathrm{CQ} \mathrm{IC}_{50}$ in $\mathrm{C}^{\mathrm{Dd} 2}$ (Fig. $2 \mathrm{~F}$ ).

\section{Effect of moderating intracellular GSH levels on $C Q$ accumulation}

The $\mathrm{C} 2^{\mathrm{GC} 03}$ and $\mathrm{C} 3^{\mathrm{Dd} 2}$ lines were treated with 1-chloro-2, 4-dinitrobenzene (CDNB), a substrate for glutathione $S$-transferase (GST) that leads to the formation of 2,4-dinitrophenyl-Sglutathione adducts, which are excreted, and thus result in a decrease of intracellular GSH levels $(22,28)$, and their effect on accumulation of CQ was measured. Increasing concentrations of $\mathrm{CDNB}$ to just above the $\mathrm{IC}_{50}$ concentrations $(8.5 \pm 4.5 \mu \mathrm{M}$ and $9.5 \pm 1.1 \mu \mathrm{M}$ for $\mathrm{C}^{\mathrm{GC} 03}$ and $\mathrm{C} 3{ }^{\mathrm{Dd} 2}$, respectively) significantly stimulated the accumulation of $\left[{ }^{3} \mathrm{H}\right]-\mathrm{CQ}$ in the CQR parasite line $\mathrm{C}^{\mathrm{Dd} 2}$, but not in the CQS line $\mathrm{C}^{\mathrm{GC} 03}$ (Fig. $3 \mathrm{~A}$ ). The $\mathrm{CDNB}$ effect on $\left[{ }^{3} \mathrm{H}\right]-\mathrm{CQ}$ accumulation in CQR parasites was similar to that caused by $10 \mu M$ verapamil (VP) (Fig. 3A), which is an L-type calcium channel blocker known to interact with mutated forms of PfCRT $(18,26,33,42)$. In contrast, $\left[{ }^{3} \mathrm{H}\right]-\mathrm{CQ}$ accumulation in CQS $\mathrm{C}^{\mathrm{GCO}}{ }^{\mathrm{G}}$ was unaffected by $\mathrm{CDNB}$ or VP (Fig. 3A). Qualitatively similar results were obtained comparing a CQS back-mutant parasite line derived from a CQR parent line (Dd2) called T76K-1 ${ }^{\mathrm{Dd} 2}$ (Table 1) with the CQR C-1 ${ }^{\text {Dd2 }}$ (Table 1) (Fig. 3B) (18). The effect of $10 \mu \mathrm{M}$ CDNB and VP was negligible in the CQS T76K-1 ${ }^{\mathrm{Dd} 2}$, whereas the effects on the $C Q R$ line $C-1^{D d 2}$ were similar to that observed with $C 3^{D d 2}$ (Fig. 3B). It was confirmed that incubation with $20 \mu M \mathrm{CDNB}$ for $20 \mathrm{~min}$ (the same incubation time as in the cellular accumulation ratio for chloroquine experiment described above) resulted in significantly reduced GSH levels (Fig. 3C). These data show that the reduced GSH levels resulting from CDNB treatment impact on CQ accumulation, but only in parasites carrying the K76T mutation in the $p f c r t$ allele. An alternative explanation could be that the 2,4-dinitrophenyl-S-glutathione adduct generated itself interferes with CQ movement through mutant PfCRT in a similar way to VP.

\section{$C Q$ equilibrium binding studies and the concentration of hemozoin}

The data detailed above suggested that cytoplasmic GSH may have access to the DV in CQR parasites and thus be able to interact with the free heme there to form a GSH-heme complex, possibly with the neutral thiol serving as an axial ligand to heme iron as suggested by Shviro and Shaklai (41). This interaction would scavenge free heme and slow down the rate of hemozoin formation, but as the GSH-heme complex is nontoxic (41), it would not damage the parasite, and would also compete with CQ for binding to the heme target and so reduce the toxicity of CQ. In addition, it is possible that some of the heme could be spontaneously destroyed by GSH, liberating iron and GSSG $(1,41)$, which would also result in reducing CQ binding and so its antimalarial effectiveness.

For these reasons, we postulated that the amount of free heme in the DV of CQR parasite lines should be reduced. It is difficult to measure directly the concentration of free heme in the DV of $P$. falciparum, but its concentration can be reliably estimated from analysis of the CQ equilibrium binding experiments performed on intact infected erythrocytes $(4,5,9)$. The basis of this assay is that CQ readily forms a complex with free heme and so prevents its biomineralization into hemozoin (3, 5). Our analysis of the apparent affinity of CQ binding to heme demonstrated that it is greatly reduced in the CQR lines $C 3^{\mathrm{Dd} 2}$ and $\mathrm{C}^{7 \mathrm{G} 8}$ compared to the $\mathrm{C} 2^{\mathrm{GCO}}$ CQS line (Fig. 3D), with both reduced apparent affinity and also reduced heme-binding capacity. Least-squares analysis of the CQ-binding isotherms indicates that CQ equilibrium binding capacity is lower in $\mathrm{C}^{\mathrm{Dd} 2}$ and $\mathrm{C}^{7 \mathrm{G} 8}$ isolates $(30 \pm 0.8 \mu \mathrm{M}$ and $29 \pm 1.7 \mu \mathrm{M}$, respectively) compared to $\mathrm{C}^{\mathrm{GC} 03}(35 \pm 1.1 \mu \mathrm{M})$. This is consistent with free heme availability being less, although only by about $15 \%$, in these two CQR lines and potentially linked to mutations in PfCRT. The decreases are also consistent with the 15\%-20\% reduction in CQ-binding capacity reported in the CQR progeny of a genetic cross [reported as $J_{\max }$ in Sanchez et al. (40)].

We also determined hemozoin levels in the CQS and CQR lines, and showed that they were significantly lower $(p<0.001)$ in CQR C3 ${ }^{\mathrm{Dd} 2}$ compared with CQS C2 ${ }^{\mathrm{GCO} 3}$ (Fig. $3 \mathrm{E})$. Consistent with the model, we propose that GSH in CQR parasites scavenges or destroys free heme. It should be noted that a report by Gligorijevic and colleagues (15) concluded that there was no difference in the hemozoin content between untransformed GC03 and transformed $\mathrm{C}^{\mathrm{Dd} 2}$. In that study, hemozoin quantity was determined indirectly from the volume of the malaria pigment as measured microscopically, whereas we used a quantitative chemical assay. This may suggest that pigment volume and hemozoin content are not linearly correlated.

\section{Expression of GSH biosynthesis and GSH-dependent enzymes}

To investigate whether the lower levels of GSH observed in the untreated lines with the mutant CRT could result from differential expression of GSH biosynthetic genes, real-time quantitative polymerase chain reaction (RT-PCR) of $p f g s$ and $p f \gamma g_{C S}$ was undertaken. This revealed only slight variations in the expression of these genes between parasite lines (Fig. 4A), ruling out that the different GSH levels were a consequence of reduced GSH biosynthesis in the CQR parasites. Moreover, the levels of expression of $p f c r t$ mRNA were equivalent in the four 
A

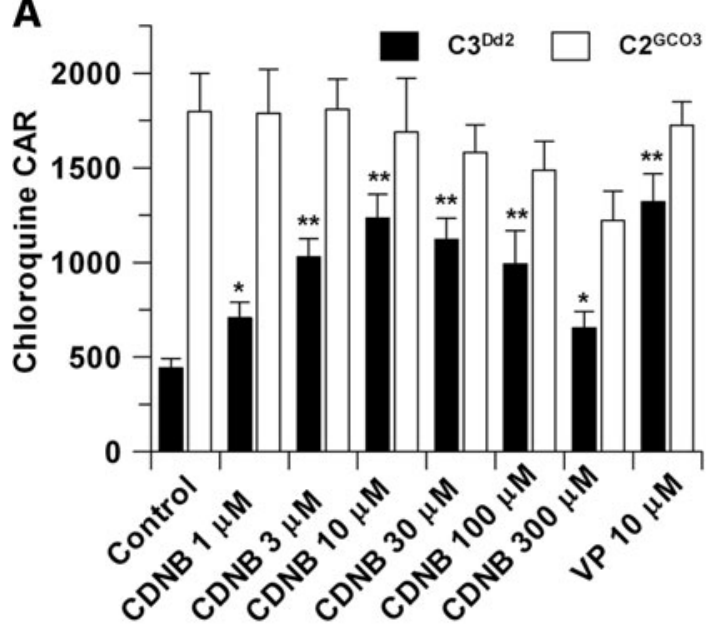

C

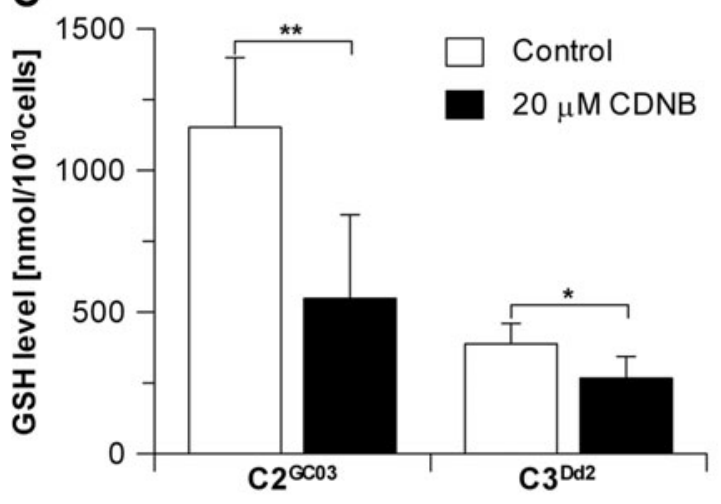

E

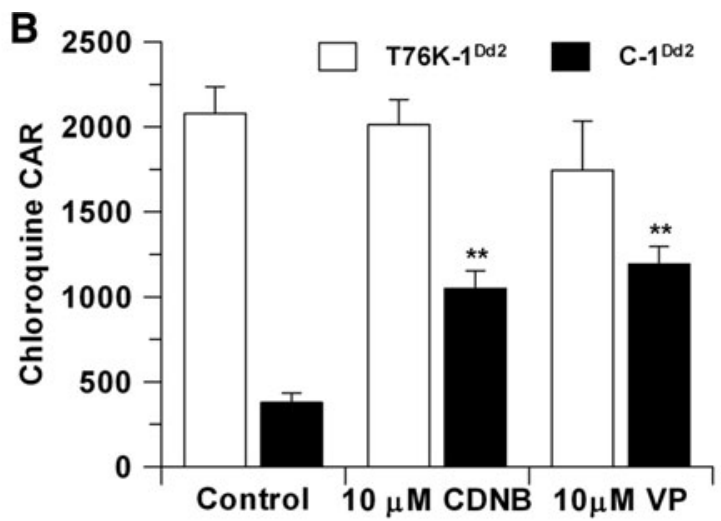

D

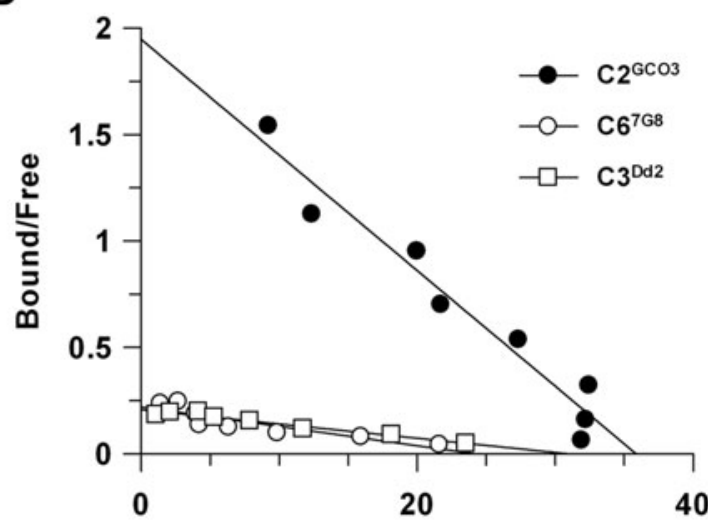

Bound $C Q[\mu \mathrm{M}]$

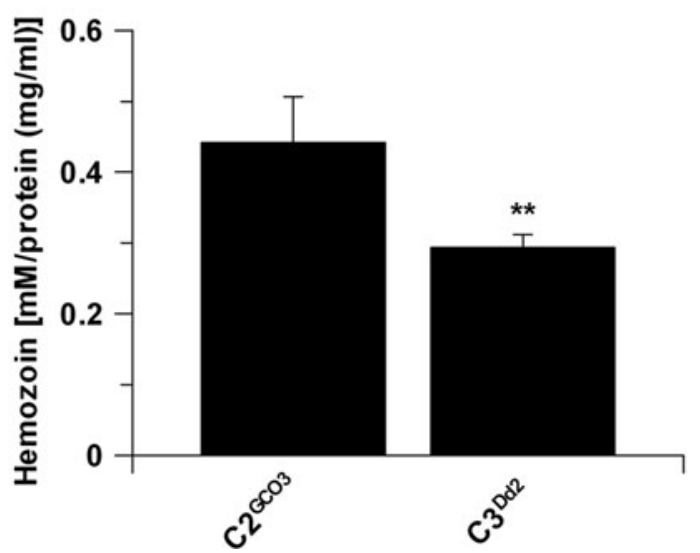

FIG. 3. Differential effect of 1-chloro-2,4-dinitrobenzene (CDNB) on CQ accumulation and differences in CQ binding between CQ-sensitive (CQS) and CQ-resistant (CQR) lines. (A) The effect of a range of concentrations of CDNB on the steady-state cellular accumulation ratio (CAR) of $\left[{ }^{3} \mathrm{H}\right]-\mathrm{CQ}$ in the $\mathrm{C} 2{ }^{\mathrm{GC} 03} \mathrm{CQS}$ line (open bars) and the C3 ${ }^{\mathrm{Dd} 2} \mathrm{CQR}$ line (filled bars). Significant differences to the control are indicated by ${ }^{*}(p<0.05)$ and ${ }^{* *}(p<0.01)$. Statistical analysis was performed using one-way ANOVA with Newman-Keuls post-test. The effect of $10 \mu \mathrm{M} C D N B$ is comparable to that of $10 \mu M$ verapamil (VP). (B) The effect of $10 \mu M$ CDNB on CAR of [ $\left.{ }^{3} \mathrm{H}\right]-C Q$ in the T76K- $1^{\text {Dd2 }}$ back-mutant CQS line (open bars) and the C-1 ${ }^{\text {Dd2 }}$ CQR line (filled bars) and the comparative effect of $10 \mu M$ VP $(* * p<0.01)$. (C) Effect of $20 \mu M$ CDNB on the levels of GSH in the isogenic parasite lines differing in their PfCRT allele. The parasites were incubated for 20 min before GSH levels were determined $\left({ }^{*} p<0.05\right)$. (D) Scatchard plot of CQ equilibrium binding in the $\mathrm{C} 2{ }^{\mathrm{GC} 03} \mathrm{CQS}$ line (filled circles), the C3 ${ }^{\mathrm{Dd} 2} \mathrm{CQR}$ line (open squares), and the $C 6^{7 \mathrm{G} 8} \mathrm{CQR}$ line (open circles). Data are means of single observations derived from five individual experiments. (E) Normalized hemozoin content of the $\mathrm{C} 2{ }^{\mathrm{GC} 03} \mathrm{CQS}$ and $\mathrm{C} 3{ }^{\mathrm{Dd} 2} \mathrm{CQR}$ lines. Data represent means \pm S.D. of 10 individual preparations of hemozoin normalized to parasite protein concentration $\left({ }^{* *} p<0.01\right.$; one-way ANOVA with Newman-Keuls post-test). 

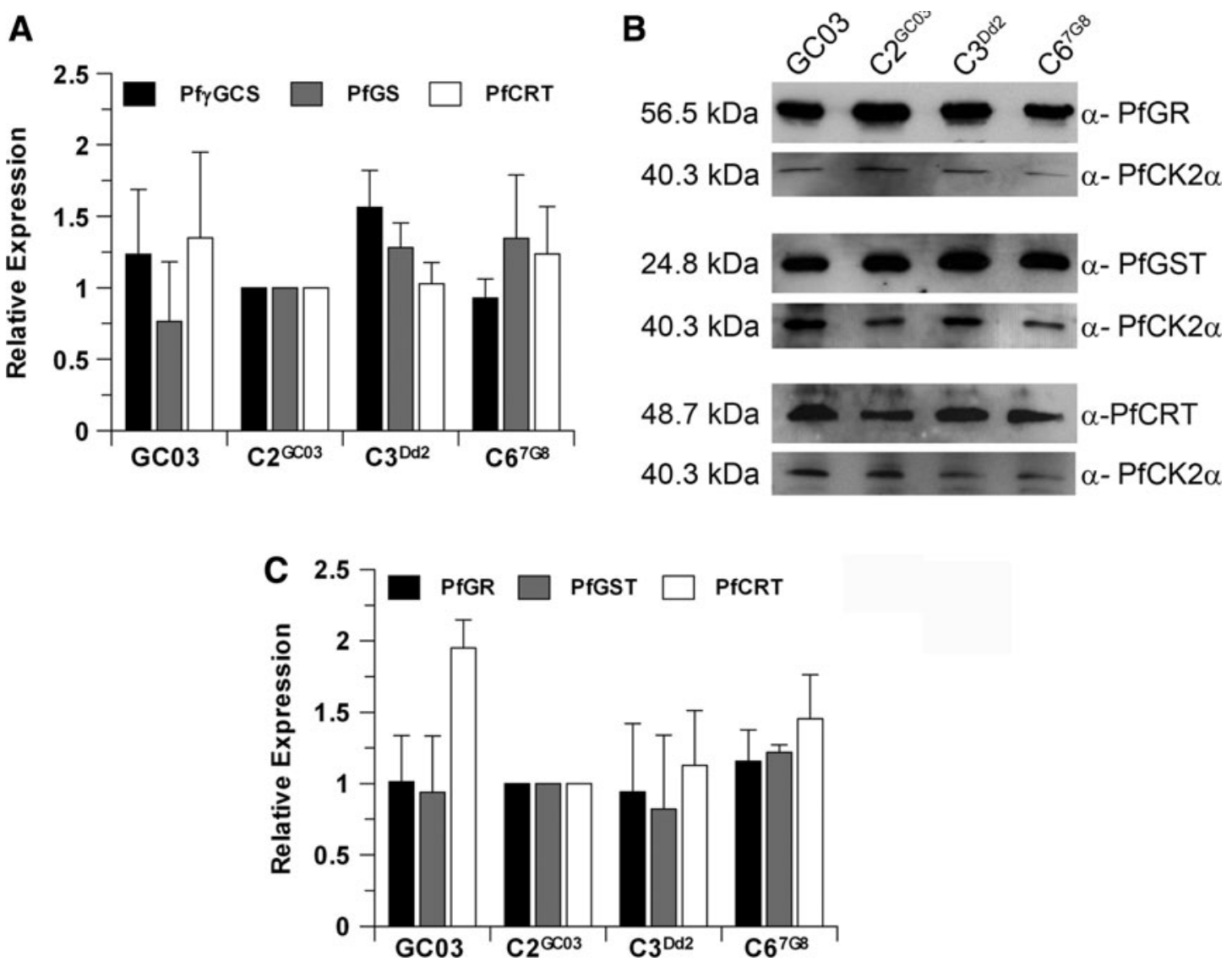

FIG. 4. Expression level of GSH biosynthesis genes, GSH-dependent proteins, and Plasmodium falciparum chloroquine resistance transporter (PfCRT). (A) The expression levels of $\gamma g c s, g s$, and $p f c r t$ in $\mathrm{GC} 03, \mathrm{C} 3^{\mathrm{Dd} 2}$, and $\mathrm{C}^{7 \mathrm{G} 8}$ were analyzed by real-time quantitative PCR relative to the expression levels of $C 2{ }^{G C 03}$ as outlined in the Materials and Methods section. The expression was normalized using the seryl-t-RNA message, which is uniformly expressed throughout the parasite blood-stage cycle. The data shown are means \pm S.E.M. of three independent experiments, each performed in triplicate. (B) Western blots of saponin-isolated parasite lysates of CQS and CQR parasite lines were performed with $5 \mu \mathrm{g}$ of protein per lane. The blots were probed with rabbit anti-PfGR antibodies $(1: 15,000)(\alpha$-PfGR) or rabbit anti-PfGST $(1: 5,000)(\alpha$-PfGST) to assess the level of each protein in the different parasite lines. The blots were reprobed with rabbit anti-PfCK2a $(\alpha-\mathrm{PfCK} 2 \mathrm{a})$ diluted 1:200 to control for equal loading. (C) The relative expression of proteins shown in B was analyzed using LabImage 1D, and the data represent the normalized mean values obtained from three to four independent western blots \pm S.D. Protein expression levels showed no significant differences.

parasite lines. In addition, PfCRT protein expression, as determined by western blotting, was similar in the three isogenic lines $\mathrm{C} 2^{\mathrm{GC} 03}, \mathrm{C} 3^{\mathrm{Dd} 2}$, and $\mathrm{C} 6^{7 \mathrm{G} 8}$, while the parent line $\mathrm{GC} 03$ contained 1.5-fold to 2-fold higher levels of PfCRT protein (Fig. $4 \mathrm{~B}, \mathrm{C})$, which is consistent with previous reports by Sidhu and colleagues (42). The levels of $P$. falciparum glutathione- $S$ transferase (PfGST) and P. falciparum glutathione reductase (PfGR) proteins were similar in all parasite lines (Fig. 4B, C), suggesting that the CQR parasites preserve their capacity to maintain their redox status through the action of PfGR and to generate conjugates with GSH through the activity of PfGST. One caveat is that we cannot exclude the possibility that PfGST activity might be negatively affected by the lower GSH levels in the CQR parasite lines.

\section{GSH transport activity of PfCRT expressed in Xenopus oocytes}

The data above demonstrate that the presence of mutant $p f c r t$ leads to a reduction in intracellular GSH levels in CQR parasites without any alterations in GSH metabolism. Further, the mutant allele is required to demonstrate an effect of CDNB on CQ accumulation and to show an increase in CQ $\mathrm{IC}_{50}$ values in the presence of NAC. We thus hypothesized that these effects are mediated by selective transfer of GSH to the DV, the site of CQ action, possibly via transport by mutant PfCRT that is located in the DV membrane (49). This hypothesis was tested using the X. laevis heterologous expression system to express mutant and wild-type forms of PfCRT. This system has been previously validated experimentally as being suitable for measurement of GSH uptake in a study of a family of PfCRT-like proteins occurring in Arabidopsis thaliana (AtCLT), which are GSH transporters (27). Further evidence for the suitability of the assay system was provided by measuring the uptake of $\left[{ }^{3} \mathrm{H}\right]-\mathrm{CQ}$ into oocytes expressing the PfCRT $^{\text {Dd2 }}$ variant (26)

We expressed several PfCRT variants in Xenopus oocytes: $\mathrm{PfCRT}^{\mathrm{HB} 3}$ as a representative of the CQS wild-type allele of $p f c r t$, as carried by $\mathrm{C} 2^{\mathrm{GC} 03}$; $\mathrm{PfCRT}{ }^{\mathrm{Dd} 2}$ as the predominant $\mathrm{CQR}$ mutant from Southeast Asia and the PfCRT isoform found in 


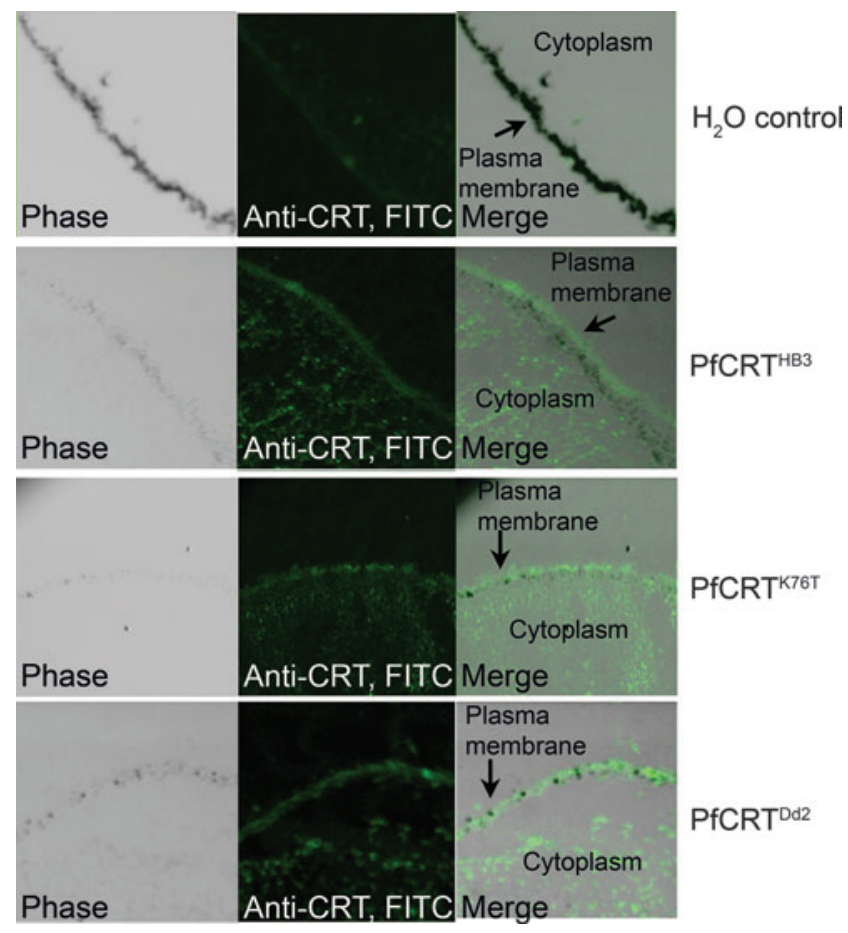

FIG. 5. Functional expression of PfCRT in Xenopus oocytes. Indirect immunofluorescence images of individual $X$. laevis oocytes after sectioning, fixing, and probing with the primary anti-PfCRT (1:500) (11) and the secondary anti-rabbit (1:500) IgG antibodies. Images shown are phase contrast (left panel), secondary antibody fluorescence (center panel), and merged (right panel). Images are presented for waterinjected control oocytes and oocytes expressing the HB3, K76T, and Dd2 variants of PfCRT (top to bottom). The plasma membrane and cytoplasm are labeled.

$\mathrm{C}^{\mathrm{Dd} 2}$; PfCRT ${ }^{\mathrm{K} 76 \mathrm{~T}}$ as it carries only the single K76T mutation, but is otherwise wild type (a form that has no corollary in parasite isolate lines); $A$. thaliana CLT1 (AtCLT1) as a positive control. Indirect immunofluorescence was performed using anti-PfCRT as the primary antibody (11). The images demonstrated that $\mathrm{PfCRT}^{\mathrm{HB} 3}$, $\mathrm{PfCRT}^{\mathrm{K} 76 \mathrm{~T}}$, and $\mathrm{PfCRT}^{\mathrm{Dd} 2}$ were all expressed in the oocytes injected with the cRNA of their respective genes (Fig. 5). Immunofluorescence is visible at the plasma membrane and also in the cytoplasm at comparable levels for all three PfCRT variants. There is no fluorescence signal in the water-injected control group.

We confirmed previous reports that oocytes expressing $\mathrm{PfCRT}^{\mathrm{Dd} 2}$ demonstrated a two-threefold increase in $\left[{ }^{3} \mathrm{H}\right]-\mathrm{CQ}$ uptake compared to water-injected controls, an effect that was time dependent (Fig. 6A) (26). The X. laevis oocytes possess a low endogenous ability to take up GSH, which has been observed in previous studies $(21,27)$. The expression of PfCRT $^{\text {Dd2 }}$, however, conferred time-dependent transport of $\left[{ }^{3} \mathrm{H}\right]-\mathrm{GSH}$, which was reduced to basal levels in the presence of CQ (Fig. 6B). PfCRT ${ }^{\mathrm{Dd} 2}$ and PfCRT ${ }^{\mathrm{K} 76 \mathrm{~T}}$ showed six- and twofold higher rates of GSH membrane transport than waterinjected controls. [ $\left.{ }^{3} \mathrm{H}\right]-\mathrm{GSH}$ uptake into oocytes expressing PfCRT $^{\mathrm{Dd} 2}$ or PfCRT ${ }^{\mathrm{K} 76 \mathrm{~T}}$ was specific, with transport inhibited by saturating concentrations of unlabeled GSH, CQ, and VP (Fig. 6D). No transport of $\left[{ }^{3} \mathrm{H}\right]-\mathrm{GSH}$ was detected in oocytes expressing PfCRT ${ }^{\mathrm{HB} 3}$, showing that only the CQR isoforms of
PfCRT transport GSH (Fig. 6C). Thus, these findings strongly support the proposal that the mutant PfCRT occurring in CQR parasites transport GSH.

\section{Discussion}

It is widely acknowledged that resistance to $\mathrm{CQ}$ is primarily conferred by mutations in the $P$. falciparum transporter gene $p f c r t(11,17,42,49)$, although other factors, including the multidrug-resistant transporter homolog pfmdr1, also contribute to the level of CQR $(32,37)$. This current study reevaluated the hypothesis that GSH plays a part in CQR (14) and has revealed a previously unconsidered role for the CQR alleles of $p f c r t$. GSH was reported previously to scavenge free heme, forming a complex in which the thiol group is linked to heme iron, and provides a mechanism to protect membranes from oxidative heme damage (41). CQ also binds to heme, inhibiting the detoxification of heme into hemozoin crystals and causing a build-up of a drug-heme complex $(4,9,18,20$, 50). This CQ-heme complex is toxic, in contrast to the GSHheme complex, promoting lipid peroxidation and destruction of parasite membranes and mediates parasite killing by CQ (41). Thus, it can be envisaged that GSH could interfere with CQ action simply by competing for binding with heme. It has also been reported that GSH degrades heme in vitro $(1,41)$; if this happens in situ, then GSH would interfere with CQ action by destroying its target. A third possibility whereby GSH could play a role is that it may protect parasites from enhanced heme-induced oxidative stress (2). Our data showing that CQR P. falciparum contains reduced levels of hemozoin are consistent with free heme being either scavenged or degraded by GSH in these parasites. However, until now, it was not clear how modulating the levels of GSH, which is synthesized in the cytoplasm of the parasites, can influence the sensitivity to $C Q$, which acts within the DV of the parasites where heme is generated.

Our findings in this study resolve this issue and reveal a new role for mutant PfCRT in transporting GSH between the cytoplasm and the DV, presumably leading to a change in the overall distribution of the tripeptide. We demonstrate direct and specific transport of GSH by two CQR isoforms (K76T and Dd2) of PfCRT expressed in X. laevis oocytes. Further evidence for mutant PfCRT-driven GSH transport is provided by selective inhibition of GSH uptake by both CQ and VP. GSH transport by CQR alleles of pfcrt is in agreement with a previous report that the CQR mutant PfCRT ${ }^{\mathrm{Dd} 2}$ is capable of transporting small peptides as well as CQ (26). In fact, we found that a single-point mutant PfCRT ${ }^{\mathrm{K} 76 \mathrm{~T}}$ was sufficient to allow uptake of $\left[{ }^{3} \mathrm{H}\right]-\mathrm{GSH}$, although not to the same level as the mutant PfCRT ${ }^{\mathrm{Dd} 2}$ allele. In contrast, we could not demonstrate any $\left[{ }^{3} \mathrm{H}\right]-\mathrm{GSH}$ transport activity in oocytes expressing the CQS allele of $p f c r t$. The only other study in which $p f c r t$ has been expressed in oocytes is that reported by Martin and colleagues (26) studying CQ transport. In that study, the $p f c r t$ sequence had to be modified extensively to achieve functional expression of the protein in the oocyte system. This was not necessary in the current study where we see adequate and functionally relevant PfCRT protein in the oocyte plasma membrane as well as the oocyte cytoplasm using the unmodified pfcrt codon sequence. A further discrepancy between the data presented here for GSH transport and CQ transport reported by Martin and colleagues (26) is that they 
A

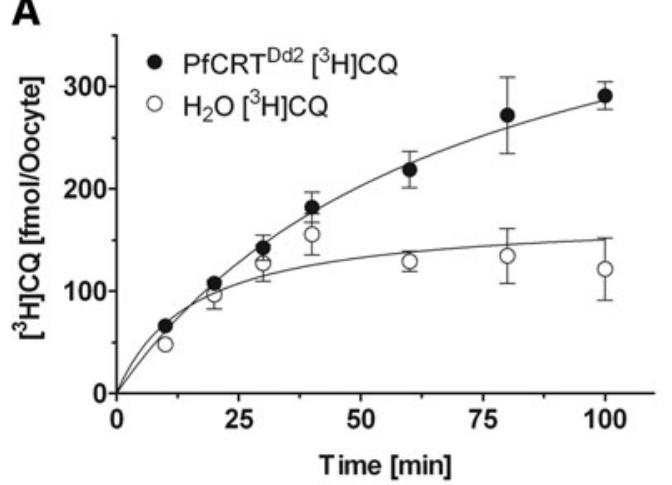

C

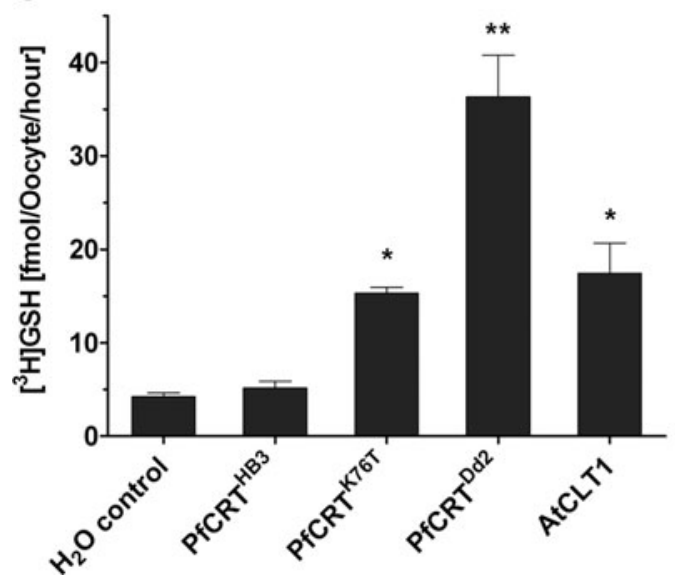

B

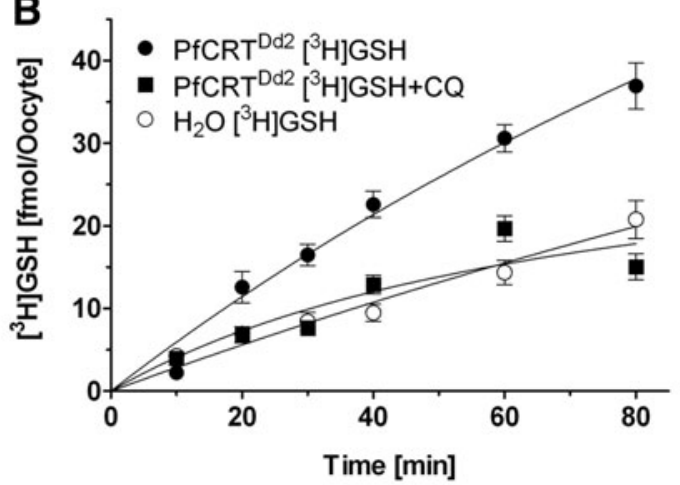

D

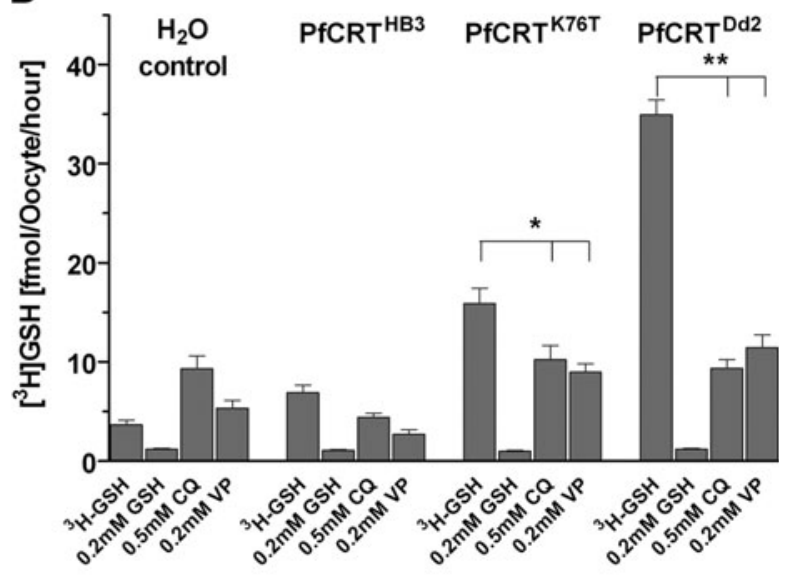

FIG. 6. Uptake of $\left[{ }^{3} \mathrm{H}\right]-\mathrm{GSH}$ by Xenopus oocytes expressing mutant and wild-type PfCRT and Arabidopsis thaliana CLT1. (A) Time course of uptake of $\left[{ }^{3} \mathrm{H}\right]-\mathrm{CQ}$ in oocytes expressing the mutant PfCRT ${ }^{\mathrm{Dd} 2}$ (filled circles) in comparison to the water control (open circle). (B) Time course of uptake of $\left[{ }^{3} \mathrm{H}\right]-\mathrm{GSH}$ in oocytes expressing PfCRT ${ }^{\mathrm{Dd} 2}$ in the absence (filled circles) or presence (filled squares) of $0.5 \mathrm{mM}$ unlabeled CQ in comparison to the water controls (open circles). Data are means \pm S.E.M. from four individual experiments with oocytes from different frogs and with six or more injected oocytes at every time point $(n \geq 24)$. GSH accumulation was significantly greater in PfCRT ${ }^{\mathrm{Dd}}$ compared with water-injected controls or $\mathrm{PfCRT}^{\mathrm{Dd} 2}$ in the presence of CQ $\left({ }^{*} p<0.01\right.$, Mann-Whitney U-test). (C) Uptake of $\left[{ }^{3} \mathrm{H}\right]$-GSH in oocytes expressing PfCRT ${ }^{\mathrm{HB} 3}$, $\mathrm{PfCRT}^{\mathrm{K} 76 \mathrm{~T}}$, or PfCRT ${ }^{\mathrm{Dd} 2}$ variants, together with the positive control from A. thaliana (AtCLT1). Data are means \pm S.E.M. from five individual experiments with oocytes from different frogs and with seven or more injected oocytes per group (PfCRT isoform or water control) $(n \geq 35)$. The PfCRT ${ }^{\mathrm{Dd} 2}$-expressing oocytes showed significantly higher uptake of GSH than the water control $\left({ }^{* *} p<0.001\right.$, Mann-Whitney $U$-test). A similar trend was observed for PfCRT ${ }^{\mathrm{K} 76 \mathrm{~T}}$ and AtCLT1 $\left({ }^{*} p<0.01\right.$, MannWhitney $U$-test). In contrast, uptake by $\mathrm{PfCRT}^{\mathrm{HB} 3}$ was not significantly different to the water-injected controls. (D) Inhibitory effect of unlabeled GSH $(0.2 \mathrm{mM}), \mathrm{CQ}(0.5 \mathrm{mM})$, and VP $(0.2 \mathrm{mM})$ on the uptake of $\left[{ }^{3} \mathrm{H}\right]-\mathrm{GSH}$ in oocytes expressing PfCRT ${ }^{\mathrm{Dd2}}$, $\mathrm{PfCRT}^{\mathrm{K} 76 \mathrm{~T}}$, and PfCRT ${ }^{\mathrm{HB} 3}$, compared with a water control. Data are means \pm S.E.M. from three individual experiments with oocytes from different frogs and with seven or more injected oocytes per group $(n \geq 21)$. In the presence of either CQ or VP, the uptake of $\left[{ }^{3} \mathrm{H}\right]-\mathrm{GSH}$ in oocytes expressing PfCRT ${ }^{\mathrm{Dd} 2}$ was significantly reduced $\left({ }^{* *} p<0.001\right.$, Mann-Whitney $U-$ test). A similar trend, although less pronounced, was observed for $\operatorname{PfCRT}^{\mathrm{K} 76 \mathrm{~T}}\left({ }^{*} p<0.05\right.$, Mann-Whitney $U$-test). The specificity of the uptake observed in all experimental groups is verified by the reduction of $\left[{ }^{3} \mathrm{H}\right]-\mathrm{GSH}$ uptake to background levels by the coincubation with $0.2 \mathrm{mM}$ unlabelled GSH.

found the single-point mutant of PfCRT ${ }^{\mathrm{K} 76 \mathrm{~T}}$ incapable of $\mathrm{CQ}$ transport. Our conclusion is that the K76T mutation in PfCRT generates structural changes that are sufficient to allow GSH transport, but not CQ transport. It is not clear what orientation PfCRT takes when inserted into the oocyte membrane; our results suggest that the majority of the protein has an orientation that is equivalent to that in the DV, or alternatively, the transporter can move GSH in either direction, depending on the prevailing concentration gradient.

Mutant PfCRT has been postulated to act either as a channel, permitting the mediated and fast transport of diprotonated CQ across the DV membrane, or as an outwardly directed slower CQ carrier $(6,26,35,39)$. The transport of GSH is time dependent, but appears to be nonsaturable, which could suggest that the transport is not carrier mediated. Another possibility is that the tripeptide is metabolized by $X$. laevis oocytes, and thus a thermodynamic equilibrium cannot be reached. In either case, the inhibition of GSH transport by CQ and the inhibition of CQ transport by small peptides (26) suggest that CQ and certain peptides, including GSH, share the same translocation sites within mutant PfCRT.

The functional relevance of mutant PfCRT-mediated GSH transport is revealed when GSH levels are elevated in both CQR and CQS parasite lines using NAC, leading to a significant 
increase of the CQ IC 50 values only in CQR lines (Fig. 2). Increased cytoplasmic GSH appears to only access the DV compartment in the CQR parasites, which is consistent with the data presenting GSH transport by mutant PfCRT in situ.

Conversely, the GST substrate CDNB is known to reverse $\mathrm{CQR}$, and it was suggested that this was directly caused by a reduction in GSH (14). We show here that incubation of parasites with CDNB as well as reducing intracellular GSH levels also cause CQR parasites to accumulate more CQ (Fig. 3), indicating a clear role for GSH in modulating CQR. However, direct competition between the DNP-SG conjugate and CQ for PfCRT-mediated efflux cannot be completely excluded.

Substitution of mutant pfcrt alleles in otherwise isogenic backgrounds of $P$. falciparum has a marked effect on the cellular level of GSH, with CQR isogenic parasites having significantly lower levels of GSH, which is also reflected in their increased susceptibility to BSO (Fig. 2). Our data demonstrate that this is not attributable to changes in the expression of the enzymes involved in the synthesis, conjugation, and reduction of GSH (Fig. 4). Thus, the differences observed in GSH levels are most readily explained as a direct result of the different genotypes of $p f c r t$. We suggest that cytoplasmic GSH is transported into the DV in parasites expressing mutated $p f c r t$ and that this is an important feature of CQR.

The CQR parasites contain less GSH than CQS counterparts, which superficially seems strange if this is the mediator of resistance. However, the key factor is not the level of GSH, but its location; it is the GSH in the DV that has the protective effect through binding to heme. This binding itself would reduce the amount of free GSH in the parasite overall, and also there are a multitude of peptidases in the DV, and it seems likely that they eventually destroy much of the DV-located GSH through proteolysis. Proteolysis of GSH and GS-X adducts (which could include GSH-heme) by carboxypeptidases has previously been shown to occur in plant vacuoles, but a fuller investigation of this possibility in Plasmodium was beyond the scope of this study (52).

Our findings clearly show that high GSH levels alone are not sufficient to affect CQR; it is the location of the GSH that is central to resistance. This is reiterated by our demonstration that GSH levels in untransformed Dd2 were found to be comparable with those of the CQS lines GC03 and $\mathrm{C}^{\mathrm{GC}}{ }^{\mathrm{G} 03}$. This is also supported by a previous study where two nonrelated isolates, CQS 3D7 and CQR Dd2, were compared, and higher GSH levels were reported in the resistant parasites (30). Discovery of the crucial role of the mutant PfCRT in transporting GSH will now allow fuller analyses of the part played by the protein in other CQR lines.

\section{Materials and Methods}

\section{Materials}

P. falciparum GC03, $\mathrm{C}^{\mathrm{GC} 03}, \mathrm{C}^{\mathrm{Dd} 2}, \mathrm{C}^{7 \mathrm{G} 8}, \mathrm{~T} 76 \mathrm{~K}-1^{\mathrm{Dd} 2}$, and C-1 ${ }^{\text {Dd2 }}$ were a gift from Professor D. Fidock, (New York, USA) $(18,42)$ (Table 1). The plasmids PfHSP86 5'-pENTR4/1, GFPpENTR2/3p, CHD-Hsp86, and pCHD-3/4 were a gift from Professor G. I. McFadden (Melbourne). Anti-P. falciparum glutathione $S$-transferase (PfGST) antiserum was obtained from Professor E. Liebau (University of Münster, Germany). Antiserum against $P$. falciparum casein kinase $2 \alpha$ (PfCK2a) was provided by Professor C. Doerig (Monash University, Australia) (16). RPMI 1640 medium and Albumax II were from Invitrogen. All chemicals, unless otherwise stated, were from Sigma.

\section{Parasite culture and determination of $I C_{50} s$}

Parasites were cultured according to Trager and Jensen (46), synchronized using sorbitol (19), and freed from erythrocytes using saponin (47). Parasite drug susceptibility was determined by measuring the incorporation of $\left[{ }^{3} \mathrm{H}\right]-$ hypoxanthine $(20 \mathrm{Ci} / \mathrm{mmol} ; \mathrm{ARC})$ in the presence of increasing drug concentrations (10) and modifiers of intracellular GSH concentrations as detailed in the figure legends.

\section{Localization studies}

Expression constructs pCHD- Hsp86- $\gamma$ GCS-GFP and pCHD- Hsp86-GS-GFP contained the $\gamma g_{c s}$ or $g s$ genes of $P$. falciparum cloned in frame with a $3^{\prime} g f p$ gene to generate C-terminal-tagged $\gamma$-GCS or GS fusion proteins. The chimeric genes were expressed under the control of the Pfhsp 86 promoter and were generated using the Invitrogen MultiSite Gateway system in combination with the pCHD-3/4 destination vector (48). To generate gene entry clones, the fulllength genes for $\gamma g c s$ and $g s$ were amplified using the primer pairs, defined in Table 2, using Pfx SuperMix (Invitrogen) and subcloned according to manufacturer's instructions. The Multisite Gateway LR recombination reaction was performed according to the manufacturer's instructions (Invitrogen).

\section{Determination of total GSH levels}

Intracellular GSH levels of saponin-isolated parasites were determined by HPLC (51). Cells were washed once with Earle's balanced salt solution (EBSS) $(6.8 \mathrm{~g} / 1 \mathrm{NaCl}, 0.4 \mathrm{~g} / 1 \mathrm{KCl}, 0.2 \mathrm{~g} / 1$

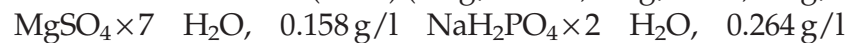
$\mathrm{CaCl}_{2} \times 2 \mathrm{H}_{2} \mathrm{O}, 2.2 \mathrm{~g} / 1 \mathrm{NaHCO}_{3}$, and $1 \mathrm{~g} / 1 \mathrm{D}$-glucose) before

Table 2. Primers Used in This Study

\begin{tabular}{|c|c|c|}
\hline Product & Forward primer $5^{\prime}$ to $3^{\prime}$ & Reverse primer $5^{\prime}$ to $3^{\prime}$ \\
\hline$\gamma g c s$ ORF & CACCATGGGTTTTCTAAAAATCGGAACG & TGCACTCAGTTCGTACATTTTTTTTGC \\
\hline gs ORF & CACCATGGAAAGAAAGGTAGATGAGTT & ATGTTCAGTTAAAAAAAAAGAATCC \\
\hline Pfcrt cDNA & ATATCTCGAGATGAAATTCGCAAG & ATATCCATGGTTATTGTGTAATAATTGAATCG \\
\hline$\gamma g c s$ RT-PCR & TCCTTGCTCTTACTGCATGTACT & TTCCGTTCTACAATCAACACTGT \\
\hline gs RT-PCR & CTTTAGAGCATTATATACACCTAACCA & CGAACCAACAAGTTGATAAGGTA \\
\hline pfcrt RT-PCR & GGAAATATCCAATCATTTGTTCTT & CAACAATAATAACTGCTCCGAGAT \\
\hline $\begin{array}{l}\text { seryl-tRNA synthase } \\
\text { RT-PCR }\end{array}$ & AAGTAGCAGGTCATCGTGGTT & TTCGGCACATTCTTCCATAA \\
\hline
\end{tabular}

RT-PCR, real-time quantitative-polymerase chain reaction. 
lysis of red blood cells (RBC) with $0.15 \%$ saponin $\left(5 \mathrm{~min}, 4^{\circ} \mathrm{C}\right)$. Isolated trophozoites $\left(2-5 \times 10^{7}\right)$ were washed 3 times with EBSS, incubated for $45 \mathrm{~min}$ at room temperature in $50 \mu \mathrm{l}$ of $40 \mathrm{mM} \quad \mathrm{N}$-(2-hydroxyethyl)-piperazine- $N^{\prime}$ (3-propanesulfonic acid) and $4 \mathrm{mM}$ diethylenetriamine pentaacetic acid, $\mathrm{pH} 8.0$, with $0.7 \mathrm{mM}$ Tris (2-carboxyethyl)-phosphine to fully reduce thiols before derivatisation with monobromobimane. Subsequently, $50 \mu \mathrm{l}$ of $2 \mathrm{mM}$ monobromobimane (dissolved in ethanol) was added, and samples were heated to $70^{\circ} \mathrm{C}$ for $3 \mathrm{~min}$ before extracts were deproteinized for $30 \mathrm{~min}$ on ice by addition of $100 \mu \mathrm{l} 4 \mathrm{M}$ methane sulfonic acid, pH 1.6. Precipitated protein was removed by centrifugation, and supernatants were subjected to thiol analyses.

\section{$C Q$ uptake and equilibrium binding assays}

CQ uptake by P. falciparum trophozoites was measured as described previously $(5,18)$. Steady-state CQ uptake was determined over $20 \mathrm{~min}$ using $5 \mathrm{nM}$ of $\left[{ }^{3} \mathrm{H}\right]-\mathrm{CQ}$ (specific activity $4.7 \mathrm{Ci} / \mathrm{mmol}$; from ARC) in the presence or absence of various concentrations of CDNB. Equilibrium binding studies were performed as described previously, using $2 \mathrm{nM}\left[{ }^{3} \mathrm{H}\right]-\mathrm{CQ}$ and a range of concentrations of unlabelled CQ (18). After correcting for nonspecific uptake (5), the resulting binding isotherms were fitted using nonlinear regression, and binding parameters calculated using the Grafit single-site ligandbinding model (Erithacus).

\section{Determination of parasite hemozoin/heme concentration}

P. falciparum-infected RBCs were saponin-lysed, and hemozoin was purified as previously described (18). The protein concentration of parasite lysates was determined using Bradford reagent following the manufacturer's instructions (BioRad). Purified hemozoin was converted into heme by dissolving in $0.5 \mathrm{~N} \mathrm{NaOH}$, and heme concentration was determined using a QuantiChrom Heme Assay kit DIHM-250 according to the manufacturer's instructions (Universal Biologicals Ltd). Hemozoin concentration was normalized to $\mathrm{mM} / \mathrm{mg}$ of protein.

\section{Expression of pfcrt in X. laevis oocytes}

pfcrt cDNA products were synthesized with Thermoscript (Invitrogen) from total RNA of $P$. falciparum and amplified by PCR (primers see Table 2) with Taq High-Fidelity polymerase (Invitrogen) following manufacturer's recommendations. Amplified $p$ fcrt (MAL7P1.27) genes from P. falciparum $\mathrm{HB} 3$ and Dd2 and a third gene only harboring the K76T mutation in the HB3 background constructed using the Quikchange sitedirected mutagenesis kit (Stratagene) were directionally cloned into the pSP64T vector (using XhoI-NcoI sites) for expression in $X$. laevis. The Atclt1 (Arabidopsis thaliana chloroquine-like transporter 1; At5g19380) gene (27) was cloned into pT7̈TS (pGEM4Z-vector; Promega), between BglII-SpeI sites.

Capped complementary RNA (cRNA) was transcribed in vitro using the SP6 or T7 Message Machine kits (Ambion) using as templates EcoRI-linearized recombinant pSP64T or SalI-linearized pT7TS plasmids, respectively. Oocytes were obtained from X. laevis mature females purchased from Xenopus Express (Vernassal). X. laevis were immersed in euthanasic concentrations $(0.5 \% \mathrm{w} / \mathrm{v})$ of ethyl 3-aminobenzoate metha- nesulfonate, and $5 \mathrm{mM}$ Tris- $\mathrm{HCl}, \mathrm{pH}$ 7.4. Ovary lobes were removed and divided into smaller sacs. Individual oocytes were isolated manually with a platinum loop (43). After two washes, oocytes were left to recover at $18^{\circ} \mathrm{C}$ for $2 \mathrm{~h}$ in oocyte Ringer's solution $\left(115 \mathrm{mM} \mathrm{NaCl}, 2 \mathrm{mM} \mathrm{KCl}, 1.8 \mathrm{mM} \mathrm{CaCl} \mathrm{Cl}_{2}\right.$, $1 \mathrm{mM} \mathrm{MgSO}, 1 \mathrm{mM} \mathrm{Na} \mathrm{HPO}_{4}, 1.18 \mathrm{mM} \mathrm{KH_{2 }} \mathrm{PO}_{4}$, and $5 \mathrm{mM}$ HEPES, $\mathrm{pH} 7.4$; or $5 \mathrm{mM}$ MES for $\mathrm{pH} 6.0$; adding $1 \mathrm{ml} / 1$ of $10,000 \mathrm{U}$ penicillin/10,000 U streptomycin solution). Stage V-VI oocytes were selected and injected the following day with $\sim 50 \mathrm{ml}$ of DEPC-treated water or cRNA solutions at $1 \mu \mathrm{g} / \mu \mathrm{l}$ using a semiautomatic injector (Drummond, Nanoject).

\section{GSH uptake assays into X. laevis oocytes}

Enzymatic defolliculation of oocytes was completed by 30min incubation in $1 \mathrm{mg} / \mathrm{ml}$ collagenase in Ringer's solution ( $\mathrm{pH}$ 7.4). Radiotracer uptake studies (12 oocytes per condition) were carried out at room temperature in $1 \mathrm{ml}$ Ringer's solution, $\mathrm{pH} 7.4$, with $2 \mu \mathrm{Ci} / \mathrm{ml}$ of $\left[{ }^{3} \mathrm{H}\right]-\mathrm{GSH}(38.6 \mathrm{Ci} / \mathrm{mmol}$; ARC) and 5\% dithiothreitol; the final concentration of GSH was $52 \mathrm{nM}$. $\left[{ }^{3} \mathrm{H}\right]-\mathrm{CQ}(4.7 \mathrm{Ci} / \mathrm{mmol} ; \mathrm{ARC})$ was used at $2 \mu \mathrm{Ci} / \mathrm{ml}$ in Ringer's solution, $\mathrm{pH} 6.0$; the final concentration was $425 \mathrm{nM}$. Uptake studies were terminated by washing the oocytes in Ringer's solution, $\mathrm{pH} \mathrm{7.4}$, at $4^{\circ} \mathrm{C}$. Individual oocytes were collected and immersed in $1 \mathrm{ml}$ of scintillation liquid. After overnight incubation, radioactivity was determined using a Wallac 1450 Microbeta scintillation counter.

\section{Indirect Immunofluorescence of $\mathrm{X}$. laevis oocytes expressing PfCRT}

Individual oocytes were immersed in $1 \mathrm{ml}$ of an optimal cutting temperature medium (RA Lamb Ltd), and snap-frozen in 2-methylbutane in liquid $\mathrm{N}_{2}$ before sections of $10 \mu \mathrm{m}$ were prepared on glass slides coated with Chrome Alum gelatin solution. Sections were fixed with cold acetone for $10 \mathrm{~min}$, followed by blocking with $4 \%$ bovine serum albumin (BSA) in phosphate-buffered saline (PBS) for $1 \mathrm{~h}$, and incubation with primary antibody (1:500 in 4\% BSA) for $1 \mathrm{~h}$. After three washes with PBS, secondary anti-rabbit antibody (1:500 in 4\% BSA) was applied for $1 \mathrm{~h}$ followed by washes as before. Samples were mounted using a VectaShield HardSet mounting medium (Burlingame) and examined by confocal microscopy (Zeiss Axiovert 200 M; L5M5 Pascal laser module).

\section{Isolation of RNA and real-time PCR}

RNA was extracted from synchronized trophozoites using Trizol according to the manufacturer's instructions (45). RNA was treated with TURBO-DNA-free before synthesis of cDNA using the RETROscript kit (both Ambion). Real-time quantitative PCR was performed using QuantiTect SYBR Green master mix (Qiagen) and primers at a final concentration of $0.3 \mu \mathrm{M}$ in a 7500 Real-Time PCR system (Applied Biosystems). Transcription levels of $\gamma g c s, g s$, and $p f c r t$ were examined using specific primers (Table 2). Seryl-t-RNA synthase was used as an endogenous control (primers see Table 2), as it is transcribed uniformly throughout the parasite life cycle $(25,38)$. PCR cycling conditions were $50^{\circ} \mathrm{C}$ for $2 \mathrm{~min}, 95^{\circ} \mathrm{C}$ for $15 \mathrm{~min}$, followed by 40 cycles of $95^{\circ} \mathrm{C}$ for $15 \mathrm{~s}, 54$ for $30 \mathrm{~s}$, and $68^{\circ} \mathrm{C}$ for $35 \mathrm{~s}$. Relative expression levels were calculated by the $\Delta \Delta C T$ method (User Bulletin 2, Applied Biosystems, www .appliedbiosystems.com). 


\section{Western blotting}

About $5 \mu \mathrm{g}$ of protein from four different parasite lines were separated on a 15\% SDS-PAGE and blotted onto nitrocellulose. The membrane was probed with the primary antibodies raised against PfGST (1:5000), P. falciparum GR (PfGR) (at 1:15,000 dilution), and an antibody raised against PfCK2a (1:200) as a loading control. The secondary anti-rabbit antibody (Promega) was used at 1:10,000 dilution, and the signals were visualized using the Immobilon Western kit (Millipore). Relative expression was analyzed using LabImage 1D software (Kapelan Bio-Imaging Solutions).

\section{Statistical analysis}

Statistical analyses were performed using GraphPad Prism 3.0. Parametric data were analyzed by one-way analysis of variance followed by Newman-Keuls post-test if differences were significant. Nonparametric data were analyzed by Mann-Whitney $U$-test. The use of the term significant in the text means a statistically significant difference $p<0.05$.

\section{Acknowledgments}

This work was supported by the Wellcome Trust [WT061173MA-SM]. The research was also supported by the European Community's Seventh Framework Programme [FP7/2007-2013] under grant agreement $N^{\circ}$ 242095. The Medical Research Council supported PGB and JES-S with the career-developing grant G0400173-69712. The Biotechnology and Biological Sciences Research Council supported SCM and JAHM under the grant BB/C515047/1. The funders had no role in study design, data collection and analysis, decision to publish, or preparation of the manuscript. The authors would like to thank Professors Hagai Ginsburg and Graham H. Coombs for critical reading of the manuscript and many helpful comments.

\section{Ethical Statement}

This work involving malaria parasites was carried out using in vitro culture of parasites with human RBCs obtained from the West of Scotland Blood Transfusion Service. Ethics approval to use donated blood for this purpose has been obtained from the Scottish National Blood Transfusion Service Review of Nontherapeutic Issues of Blood \& Components. All work on genetically modified Plasmodium falciparum has been approved by the Health and Safety Executive (GM37/K.09/ 008, "Genetic manipulation of human malaria parasites for functional genetic analyses"; HSE reference: GM37/02.5). P. falciparum wild-type and mutant parasites are contained in Category 3 facilities for all the experimental work and not released into the environment.

\section{Author Disclosure Statement}

The authors declare that no competing financial interests exist.

\section{References}

1. Atamna $\mathrm{H}$ and Ginsburg $\mathrm{H}$. Heme degradation in the presence of glutathione. A proposed mechanism to account for the high levels of non-heme iron found in the membranes of hemoglobinopathic red blood cells. J Biol Chem 270: 24876-24883, 1995.
2. Becker K, Rahlfs S, Nickel C, and Schirmer RH. Glutathione-functions and metabolism in the malarial parasite Plasmodium falciparum. Biol Chem 384: 551-566, 2003.

3. Bray PG, Hawley SR, Mungthin M, and Ward SA. Physicochemical properties correlated with drug resistance and the reversal of drug resistance in Plasmodium falciparum. Mol Pharmacol 50: 1559-1566, 1996.

4. Bray PG, Janneh O, and Ward SA. Chloroquine uptake and activity is determined by binding to ferriprotoporphyrin IX in Plasmodium falciparum. Novartis Found Symp 226: 252260; discussion 260-254, 1999.

5. Bray PG, Mungthin M, Ridley RG, and Ward SA. Access to hematin: the basis of chloroquine resistance. Mol Pharmacol 54: 170-179, 1998.

6. Cabrera M, Natarajan J, Paguio MF, Wolf C, Urbach JS, and Roepe PD. Chloroquine transport in Plasmodium falciparum. 1. Influx and efflux kinetics for live trophozoite parasites using a novel fluorescent chloroquine probe. Biochemistry 48: 9471-9481, 2009.

7. Cabrera M, Paguio MF, Xie C, and Roepe PD. Reduced digestive vacuolar accumulation of chloroquine is not linked to resistance to chloroquine toxicity. Biochemistry 48: 1115211154, 2009.

8. Chou AC and Fitch CD. Hemolysis of mouse erythrocytes by ferriprotoporphyrin IX and chloroquine. Chemotherapeutic implications. J Clin Invest 66: 856-858, 1980.

9. Chou AC, Chevli R, and Fitch CD. Ferriprotoporphyrin IX fulfills the criteria for identification as the chloroquine receptor of malaria parasites. Biochemistry 19: 1543-1549, 1980.

10. Desjardins RE, Canfield CJ, Haynes JD, and Chulay JD. Quantitative assessment of antimalarial activity in vitro by a semiautomated microdilution technique. Antimicrob Agents Chemother 16: 710-718, 1979.

11. Fidock DA, Nomura T, Talley AK, Cooper RA, Dzekunov SM, Ferdig MT, Ursos LM, Sidhu AB, Naude B, Deitsch KW, Su XZ, Wootton JC, Roepe PD, and Wellems TE. Mutations in the P. falciparum digestive vacuole transmembrane protein PfCRT and evidence for their role in chloroquine resistance. Mol Cell 6: 861-871, 2000.

12. Foote SJ, Thompson JK, Cowman AF, and Kemp DJ. Amplification of the multidrug resistance gene in some chloroquineresistant isolates of P. falciparum. Cell 57: 921-930, 1989.

13. Ginsburg H and Golenser J. Glutathione is involved in the antimalarial action of chloroquine and its modulation affects drug sensitivity of human and murine species of Plasmodium. Redox Rep 8: 276-279, 2003.

14. Ginsburg H, Famin O, Zhang J, and Krugliak M. Inhibition of glutathione-dependent degradation of heme by chloroquine and amodiaquine as a possible basis for their antimalarial mode of action. Biochem Pharmacol 56: 1305-1313, 1998.

15. Gligorijevic B, Purdy K, Elliott DA, Cooper RA, and Roepe PD. Stage independent chloroquine resistance and chloroquine toxicity revealed via spinning disk confocal microscopy. Mol Biochem Parasitol 159: 7-23, 2008.

16. Holland Z, Prudent R, Reiser JB, Cochet C, and Doerig C. Functional analysis of protein kinase CK2 of the human malaria parasite Plasmodium falciparum. Eukaryot Cell 8: 388-397, 2009.

17. Johnson DJ, Fidock DA, Mungthin M, Lakshmanan V, Sidhu AB, Bray PG, and Ward SA. Evidence for a central role for PfCRT in conferring Plasmodium falciparum resistance to diverse antimalarial agents. Mol Cell 15: 867-877, 2004.

18. Lakshmanan V, Bray PG, Verdier-Pinard D, Johnson DJ, Horrocks P, Muhle RA, Alakpa GE, Hughes RH, Ward SA, 
Krogstad DJ, Sidhu AB, and Fidock DA. A critical role for PfCRT K76T in Plasmodium falciparum verapamil-reversible chloroquine resistance. Embo J 24: 2294-2305, 2005.

19. Lambros C and Vanderberg JP. Synchronization of Plasmodium falciparum erythrocytic stages in culture. J Parasitol 65: 418-420, 1979.

20. Leed A, DuBay K, Ursos LM, Sears D, De Dios AC, and Roepe PD. Solution structures of antimalarial drug-heme complexes. Biochemistry 41: 10245-10255, 2002.

21. Li L, Lee TK, and Ballatori N. Functional re-evaluation of the putative glutathione transporters, RcGshT and RsGshT. Yale J Biol Med 70: 301-310, 1997.

22. Liebau E, Bergmann B, Campbell AM, Teesdale-Spittle P, Brophy PM, Luersen K, and Walter RD. The glutathione Stransferase from Plasmodium falciparum. Mol Biochem Parasitol 124: 85-90, 2002.

23. Lüersen K, Walter RD, and Müller S. Plasmodium falciparum-infected red blood cells depend on a functional glutathione de novo synthesis attributable to an enhanced loss of glutathione. Biochem J 346 Pt 2: 545-552, 2000.

24. Lüersen K, Walter RD, and Müller S. The putative gammaglutamylcysteine synthetase from Plasmodium falciparum contains large insertions and a variable tandem repeat. Mol Biochem Parasitol 98: 131-142, 1999.

25. Mamoun CB and Goldberg DE. Plasmodium protein phosphatase $2 \mathrm{C}$ dephosphorylates translation elongation factor 1beta and inhibits its PKC-mediated nucleotide exchange activity in vitro. Mol Microbiol 39: 973-981, 2001.

26. Martin RE, Marchetti RV, Cowan AI, Howitt SM, Broer S, and Kirk K. Chloroquine transport via the malaria parasite's chloroquine resistance transporter. Science 325: 1680-1682, 2009.

27. Maughan SC, Pasternak M, Cairns N, Kiddle G, Brach T, Jarvis R, Haas F, Nieuwland J, Lim B, Muller C, Salcedo-Sora E, Kruse C, Orsel M, Hell R, Miller AJ, Bray P, Foyer CH, Murray JA, Meyer AJ, and Cobbett CS. Plant homologs of the Plasmodium falciparum chloroquine-resistance transporter, PfCRT, are required for glutathione homeostasis and stress responses. Proc Natl Acad Sci U S A 107: 2331-2336, 2010.

28. McIlwain CC, Townsend DM, and Tew KD. Glutathione Stransferase polymorphisms: cancer incidence and therapy. Oncogene 25: 1639-1648, 2006.

29. Meierjohann S, Walter RD, and Müller S. Glutathione synthetase from Plasmodium falciparum. Biochem J 363: 833838, 2002.

30. Meierjohann S, Walter RD, and Müller S. Regulation of intracellular glutathione levels in erythrocytes infected with chloroquine-sensitive and chloroquine-resistant Plasmodium falciparum. Biochem J 368: 761-768, 2002.

31. Meister A. Glutathione metabolism and its selective modification. J Biol Chem 263: 17205-17208, 1988.

32. Mu J, Ferdig MT, Feng $X$, Joy DA, Duan J, Furuya T, Subramanian G, Aravind L, Cooper RA, Wootton JC, Xiong M, and $\mathrm{Su} \mathrm{XZ}$. Multiple transporters associated with malaria parasite responses to chloroquine and quinine. Mol Microbiol 49: 977-989, 2003.

33. Naude B, Brzostowski JA, Kimmel AR, and Wellems TE. Dictyostelium discoideum expresses a malaria chloroquine resistance mechanism upon transfection with mutant, but not wild-type, Plasmodium falciparum transporter PfCRT. J Biol Chem 280: 25596-25603, 2005.

34. Pagola S, Stephens PW, Bohle DS, Kosar AD, and Madsen SK. The structure of malaria pigment beta-haematin. Nature 404: 307-310, 2000.
35. Paguio MF, Cabrera M, and Roepe PD. Chloroquine transport in Plasmodium falciparum. 2. Analysis of PfCRT-mediated drug transport using proteoliposomes and a fluorescent chloroquine probe. Biochemistry 48: 9482-9491, 2009.

36. Raj DK, Mu J, Jiang H, Kabat J, Singh S, Sullivan M, Fay MP, McCutchan TF, and Su XZ. Disruption of a Plasmodium falciparum multidrug resistance-associated protein (PfMRP) alters its fitness and transport of antimalarial drugs and glutathione. J Biol Chem 284: 7687-7696, 2009.

37. Reed MB, Saliba KJ, Caruana SR, Kirk K, and Cowman AF. Pgh1 modulates sensitivity and resistance to multiple antimalarials in Plasmodium falciparum. Nature 403: 906-909, 2000.

38. Salanti A, Staalsoe T, Lavstsen T, Jensen AT, Sowa MP, Arnot DE, Hviid L, and Theander TG. Selective upregulation of a single distinctly structured var gene in chondroitin sulphate A-adhering Plasmodium falciparum involved in pregnancyassociated malaria. Mol Microbiol 49: 179-191, 2003.

39. Sanchez CP, Stein WD, and Lanzer M. Is PfCRT a channel or a carrier? Two competing models explaining chloroquine resistance in Plasmodium falciparum. Trends Parasitol 23: 332-339, 2007.

40. Sanchez CP, Wunsch S, and Lanzer M. Identification of a chloroquine importer in Plasmodium falciparum. Differences in import kinetics are genetically linked with the chloroquineresistant phenotype. J Biol Chem 272: 2652-2658, 1997.

41. Shviro Y and Shaklai N. Glutathione as a scavenger of free hemin. A mechanism of preventing red cell membrane damage. Biochem Pharmacol 36: 3801-3807, 1987.

42. Sidhu AB, Verdier-Pinard D, and Fidock DA. Chloroquine resistance in Plasmodium falciparum malaria parasites conferred by pfcrt mutations. Science 298: 210-213, 2002.

43. Sigel E and Minier F. The Xenopus oocyte: system for the study of functional expression and modulation of proteins. Mol Nutr Food Res 49: 228-234, 2005.

44. Slater AF and Cerami A. Inhibition by chloroquine of a novel haem polymerase enzyme activity in malaria trophozoites. Nature 355: 167-169, 1992.

45. Smith JD, Kyes S, Craig AG, Fagan T, Hudson-Taylor D, Miller LH, Baruch DI, and Newbold CI. Analysis of adhesive domains from the A4VAR Plasmodium falciparum erythrocyte membrane protein-1 identifies a CD36 binding domain. Mol Biochem Parasitol 97: 133-148, 1998.

46. Trager $W$ and Jensen JB. Human malaria parasites in continuous culture. Science 193: 673-675, 1976.

47. Umlas J and Fallon JN. New thick-film technique for malaria diagnosis. Use of saponin stromatolytic solution for lysis. Am J Trop Med Hyg 20: 527-529, 1971.

48. van Dooren GG, Marti M, Tonkin CJ, Stimmler LM, Cowman AF, and McFadden GI. Development of the endoplasmic reticulum, mitochondrion and apicoplast during the asexual life cycle of Plasmodium falciparum. Mol Microbiol 57: 405-419, 2005.

49. Waller KL, Muhle RA, Ursos LM, Horrocks P, VerdierPinard D, Sidhu AB, Fujioka H, Roepe PD, and Fidock DA. Chloroquine resistance modulated in vitro by expression levels of the Plasmodium falciparum chloroquine resistance transporter. J Biol Chem 278: 33593-33601, 2003.

50. Warhurst DC. The quinine-haemin interaction and its relationship to antimalarial activity. Biochem Pharmacol 30: 33233327, 1981.

51. Williams RA, Westrop GD, and Coombs GH. Two pathways for cysteine biosynthesis in Leishmania major. Biochem J 420: 451-462, 2009. 
52. Wolf AE, Dietz KJ, and Schroder P. Degradation of glutathione S-conjugates by a carboxypeptidase in the plant vacuole. FEBS Lett 384: 31-34, 1996.

Address correspondence to:

Prof. Sylke Müller

Institute of Infection Immunity and Inflammation

College of Medical

Veterinary and Life Sciences University of Glasgow 120 University Place

Glasgow G12 8TA

United Kingdom

E-mail: sylke.muller@glasgow.ac.uk

Prof. Stephen A. Ward Molecular and Biochemical Parasitology Group Liverpool School of Tropical Medicine Pembroke Place Liverpool L3 5QA United Kingdom

E-mail: saward@liverpool.ac.uk

Date of first submission to ARS Central, March 28, 2012; date of final revised submission, October 26, 2012; date of acceptance, November 11, 2012.

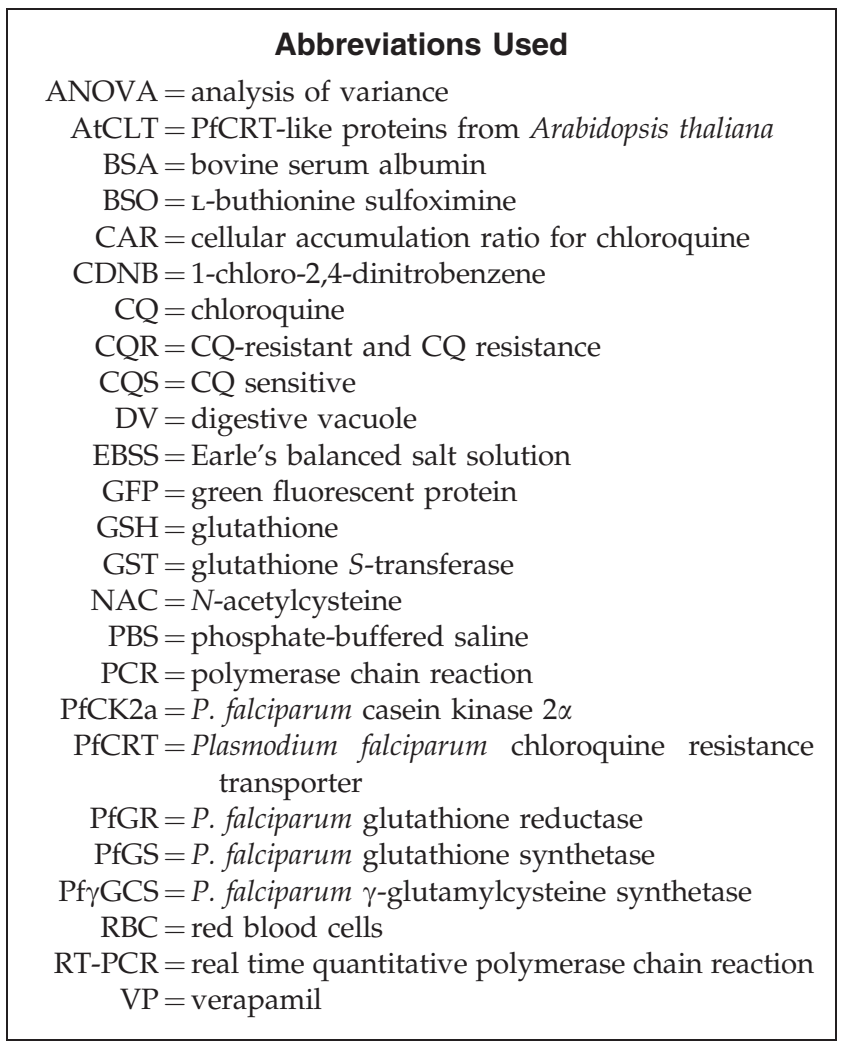

